\title{
Application of Fishbone Analysis for Evaluating Supply Chain and Business Process- A Case Study on the St James Hospital
}

\author{
Tarun Kanti Bose ${ }^{1}$ \\ ${ }^{1}$ Assistant Professor, Business Administration Discipline, Khulna University, Khulna- \\ 9208, Bangladesh \\ tarun $84 \mathrm{ku}$ ayahoo.com
}

\begin{abstract}
Conducting business is certainly not the easiest things to do in this hyper-competitive business fraternity. The scenario for the manufacturing firms is even more challenging as their value chain are the longest and widest by every considerations. Therefore, it is immensely vital for the manufacturing operators to analyze their supply chain properly so that they can establish a real good one in their armoury. The fishbone analyse is a tool for analyzing the business process and its effectiveness. It is also commonly referred as "Ishikawa Diagram" because it was invented and incorporated by Mr. Kaoru Ishikawa, a Japanese quality control statistician. It is defined as a fishbone because of its structural outlook and appearance. The fishbone analyse is a tool for analyzing the business process and its effectiveness. This study was intended towards evaluating the supply chain and business process of St. James Hospital. The analysis reveals that the problem areas are lack of proper equipment, faulty process, misdirected people, poorly materials managed, improper environment, and inefficient management.
\end{abstract}

\section{KEYWORDS}

Fishbone, St James Hospital, Business Process, Supply Chain

\section{Introduction:}

Business process is certainly a complex one and in this hyper-competitive market the complexity is even of more extremity. In this turbulence outset, every firm strive to make their every activity as efficient as possible. In doing so, they analyze and evaluate the current position and by that process they find-out areas where they can correct themselves and go forward towards obtaining excellence in operation (Southern, 1995). Over the years academicians and researchers has been working intensely to provide business operators different models and analysis tools. The objectives to provide such tools is to assists the business professionals to uncover the key issues of business and take corrective actions for continuous improvement (Balanced Scorecard Institute, 2007). Among those models "The Fishbone Analysis" is without any doubt a popular one. This study is about "The Fishbone Analysis" and its application to find out the problems and providing solutions to the case study of St James Hospital and Lucas Engineering system (Balanced Scorecard Institute, 2007).

DOI: 10.5121/ijmvsc.2012.3202 
International Journal of Managing Value and Supply Chains (IJMVSC) Vol. 3, No. 2, June 2012

\section{The Fishbone Analysis:}

The fishbone analyse is a tool for analyzing the business process and its effectiveness. It is also commonly referred as "Ishikawa Diagram" because it was invented and incorporated by Mr. Kaoru Ishikawa, a Japanese quality control statistician. It is defined as a fishbone because of its structural outlook and appearance. In normal stature it looks like a skeleton of a fish. The fishbone diagram and analysis typically evaluates the causes and sub-causes of one particular problem and therefore assists to uncover all the symptoms of any business problem (American Society for Quality, 2005). For that particular reason it is also termed as "Cause-Effect analysis". In a typical fishbone diagram the main problem which is required to be resolved has been put on the head of the diagram and the causes are put as the bones and then smaller bones are created as the resemblances of the sub-causes. Ultimately after completion of the diagram it is a comprehensive evaluation of the causes of the main problems and also reveals the root causes as well (Balanced Scorecard Institute, 2007). There are six classic categories of a fishbone diagram which are categorized as the main causes of any problems of business process. Those are people, equipment, materials, environment, management and process. The analysis of these six variables reveals the reasons of a problem irrespective of its type or severity (Ishikawa, 1986). In this study the same thing will be done for the St James Hospital and Lucas Engineering system. First of all the fishbone analysis will be done with six classic variables and in the second analysis those will be further analyzed with more causes or bones.

\section{The case Study of St James Hospital:}

This case study on St James Hospital reveals a quite interesting picture. It is about the supply chain management and directed toward achieving highest possible efficiency in that. The case study reveals that the hospital is facing immense problem to ensure sound supply chain management. There is no coordination among every action and everywhere there is haphazardness. Too many people are giving orders, sometimes they are experiencing overstocking and sometimes there is no stock to fulfil the demand of the patients, the numbers of suppliers are too many and too many people are interfering in the supply chain management system. There are other problem areas as well like staffs are not linked in the system, peoples are unwilling to share information and people are direction less. As a result the hospital is increasingly failing to maintain its well established and long lasted reputation. In this fishbone analysis the causes of the inefficient supply chain management of the hospital will be uncovered and simultaneously solution will be provided to get back to the operational excellence (Bence, 1995).

\section{The First Fishbone Analysis:}

The fishbone analysis is certainly a very good way to reveal inside picture of one particular issue. It is of great usage also to for going inside into the story and that help to detect relevant issues simultaneously (American Society for Quality, 2005). In this article first of all a very general fishbone analysis will be done by drawing the first fish bone with the six classic categories. Afterwards the major problem will be detected and the second and most important fishbone analysis will be done by putting that into the head of the second diagram. 


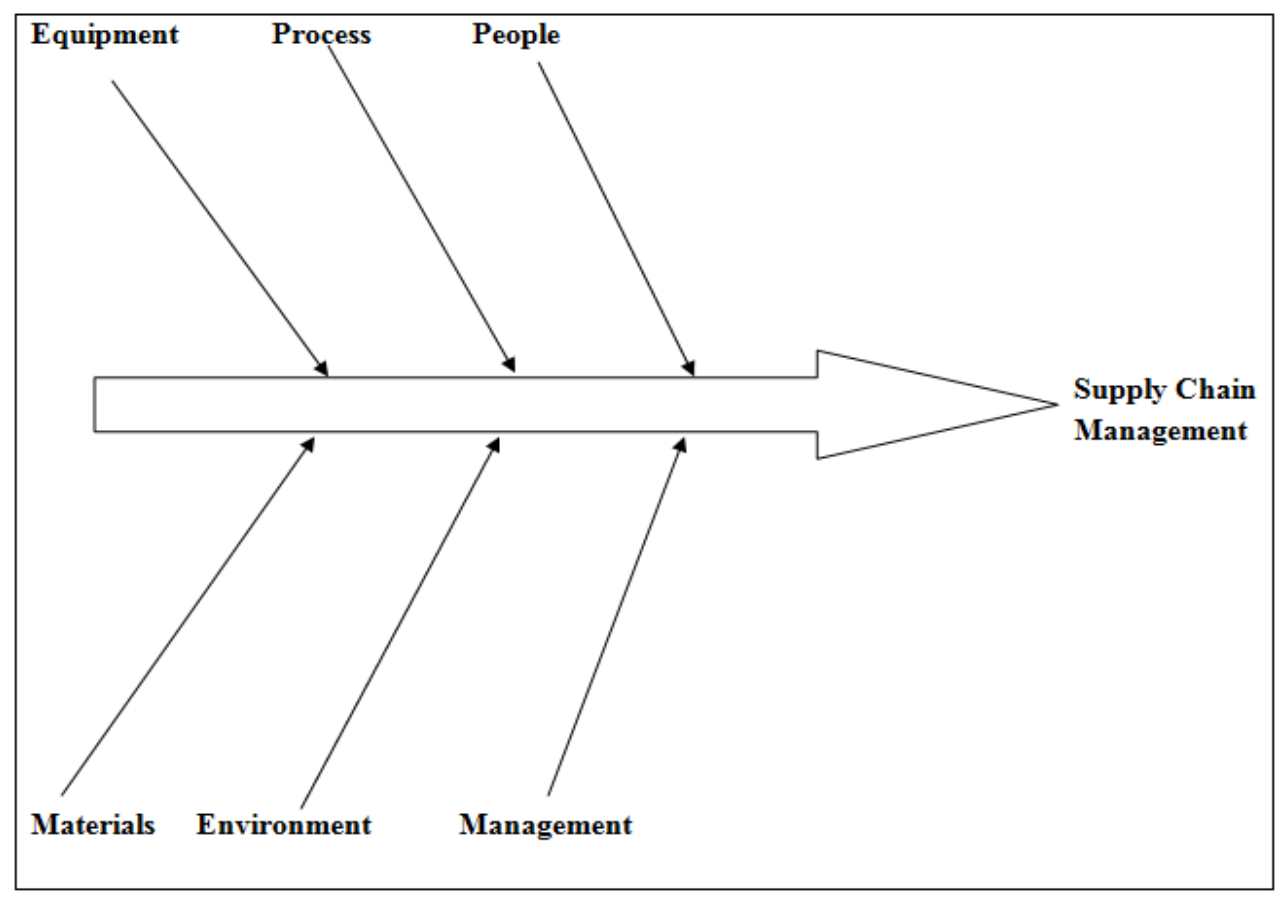

The case study of St James Hospital reveals that the major issue of the hospital that has been highlighted here is its supply chain management system. Supply chain management is comprehensively defined as the summation and integration of all the sub-systems that require providing goods or services to the customers (Gregory, 1992). Here, this hospital is a service organization and its supply chain consists of inventory management, ordering, stock-keeping, delivery, patient admission, tracking of order, information system and all other process require running the hospital smoothly. Like every organization this process has been carried out by people and it comprises of the operation of different classic items of the fishbone diagram like process, materials, equipment (Bence, 1995). In addition all of this takes place in the environmental set-up of the hospital and it carried-out by the management. The first fishbone analysis reveals that the major issue of the hospital is to ensure smooth system of supply chain. If that has been fulfilled then there is no reason why the organization can't achieve its historical success (Ishikawa, 1990). But why it is not happening? Where the problem exists? Whether peoples are inefficient, or the entire process is faulty? The second fishbone analysis will give the answer.

\section{The Second Fishbone Analysis: Why-Why Analysis:}

The fishbone analysis is a great tool to go inside and finding out the root cause. Here, in this case study the second fishbone analysis reveals that the major problem for the hospital is that the supply chain management is very much inefficient. What are the factors is making it such haphazard system? Second fishbone analysis alongside the Why-Why analysis will reveal the reasons. The evaluation will be done under the six classic categories of the fishbone diagram and analysis (Ishikawa, 1990). 
International Journal of Managing Value and Supply Chains (IJMVSC) Vol. 3, No. 2, June 2012

\subsection{Lack of Proper Equipment:}

Acquiring most suitable equipments and utilizing those properly is always the key for every operation maintenance as well as supply chain management (Otto, 1995). But an inside look at the case study reveals that one of the main causes of the inefficient supply chain management of the hospital is because of the inability of the authority to maintain and acquire proper equipment. Few equipments are not been utilized up to the fullest capacity while few are organized in a haphazard way. The people of the hospital do not have adequate IT facility to look after the equipment in a better way and they also lack technical supports. High costs of new equipment are another profound reason. Due to that factor the hospital is not been able to capture updated equipments and lagging behind the competition (Bence, 1995).

\subsection{Faulty Process:}

Efficient business process requires efficient supply chain and operation process. A sound process ensures synergy and contributed towards greater business success in product and service industry (Poli, et al., 1988). The practices of the St James Hospital reveal that they are currently undertaking a very inefficient and faulty process. The reasons of that are poor inventory management and that are causing stock out and overstocking at times. The poor execution of the process also rooted to the cause like high costs, lack of specifications, and faulty ordering system. Too many suppliers and high lead times also worsening the case (Bence, 1995).

\section{The Second Fishbone Diagram:}

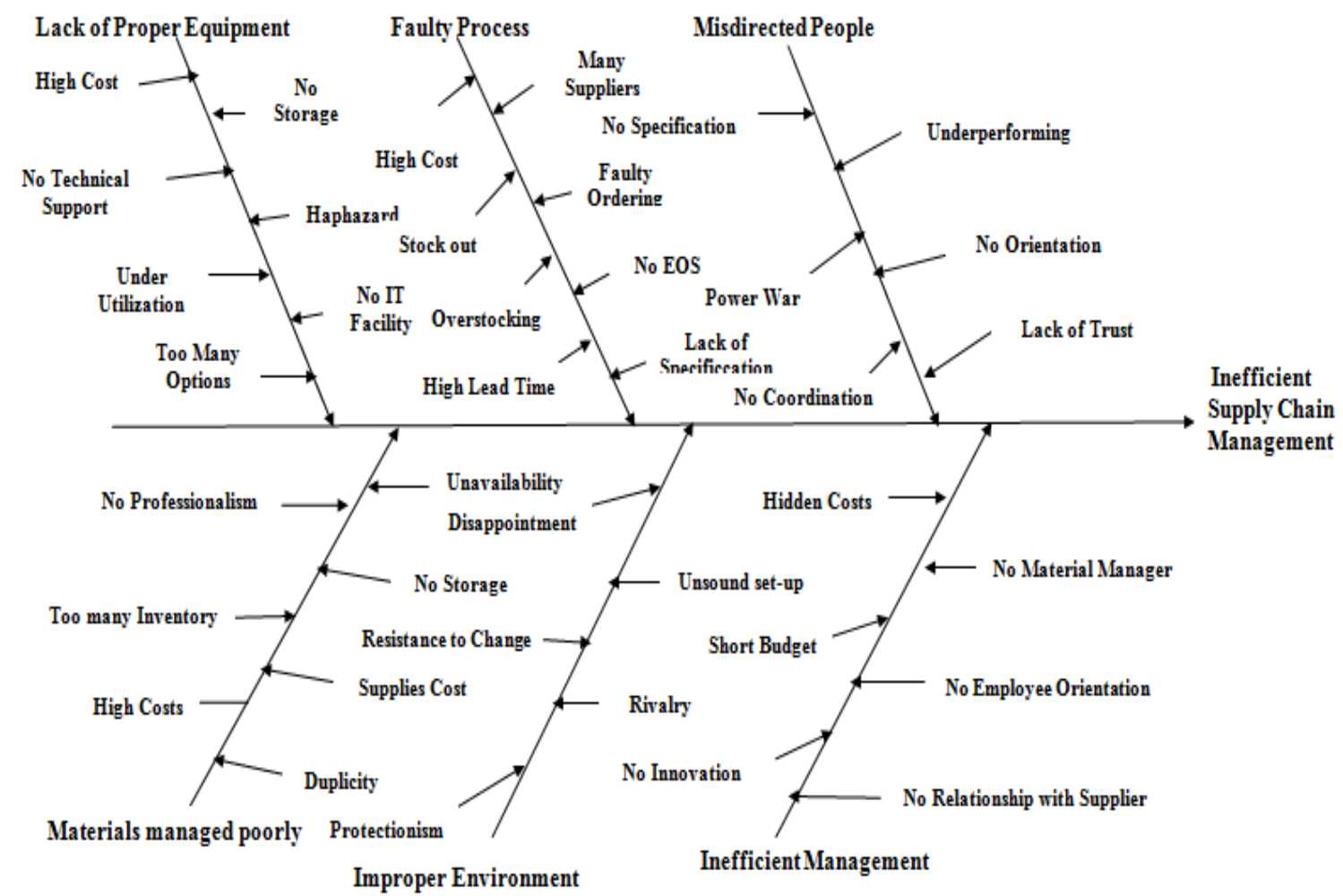


International Journal of Managing Value and Supply Chains (IJMVSC) Vol. 3, No. 2, June 2012

\subsection{Misdirected People:}

Peoples are the lifeblood of every organization. If they are not well-motivated and well-directed, it is very difficult for that organization to gain success (Sturgesand Kilani, 1992). The people of the hospital are found to be involved in power war and they are never ready to trust each other. There is no coordination among them and very few are sure about their job specifications. As a result they are failing to contribute towards the organizations goal and as a result the supply chain management system is suffering a lot and the hospital is losing is reputation (Bence, 1995).

\subsection{Materials Managed Poorly:}

Materials management is the key for ensuring smooth and high-performed supply chain management (Sturges and Kilani, 1992). The hospital of this case study is found to be managing the materials in an inept way. There is no professionalism and duplicity of the order is more frequent than ever before. The reasons of poor materials management also rooted into few serious causes like high costs of supplies, lack of proper storage capacity, unavailability of required materials at required times. It is very much essential to eliminate these problems for ensuring proper management of the materials and smooth supply chain management (Bence, 1995).

\subsection{Improper Environment:}

Business conducted in the environment and environment needs to be conducive for high level of business success (Sturges and Kilani, 1992). But for the St James Hospital environment is found to be inconvenient and as a result it is worsening the supply chain management and business process ultimately. The reasons behind it are protectionism, resistance to change, unsound set up, rivalry among employees etc (Bence, 1995).

\subsection{Inefficient Management}

Management outlines the strategies and action plans for every set of actions in products or service operation. They are virtually responsible for carrying out the business process as well as supply chain. If they are inefficient the organization has to suffer a lot. The picture of the hospital of this case study reveals the same picture. Here, the supply chain is inefficient because management is inefficient. The inside story of management's inefficiency reveals that they are suffering from hidden costs, short budget, lack of innovation, lack of employee orientation, absence of material manager, lack of relationship with suppliers etc. As a result they are not been able to keep the supply chain management system on the right track (Bence, 1995).

\section{Problems and Solutions:}

There are several reasons of inefficient supply chain management of the hospital. It is very much essential for them to solve those quickly and get rid out of the hole as soon as possible. Here, are some solutions under the six classic categories to help the hospital for improving their supply chain management. 
International Journal of Managing Value and Supply Chains (IJMVSC) Vol. 3, No. 2, June 2012

\subsection{Solutions of Equipment Problem:}

In order to solve the ongoing problems of the equipment the hospital can undertake a comprehensive program. That program will ensure that they are tracking all the equipments in a centralize information system. That will ensure higher utilization and zero wastage. The hospital also can think about hiring IT and technical experts so that those specialists can guide them about purchasing new equipments and also how to use those up to the highest extent (Bence, 1995).

\subsection{Solutions of Process Problem:}

For mitigating and resolving the process problem the hospital need to adopt an Electronic ordering system. That system will track all the stocks and will order automatically when it is necessary. The electronic system will solve the problems of overstocking, stock out as well as faulty ordering process. The hospital also needs to select specific suppliers as too many suppliers are spoiling the party (Bence, 1995). They also can undertake BPR or JIT strategy.

\subsection{Solutions of People Problem:}

Peoples are the life blood of business and it is essential for the hospital to motivate them and keep them on right track. For resolving employee issues they can undertake thorough training campaign to motivate them and train them in proper way. Coordination among all the employees also needed to be done and it is also require to specify about their individual responsibilities. After that, there is every likelihood that employees will contribute to make the supply chain productive and efficient (Bence, 1995).

\subsection{Solution of Materials Problem:}

Materials problems are also a key one which requires solutions as quick as possible. The hospital can adopt centralize ordering system to make ensure availability and eliminating duplicity of order. They can maintain strong supplier's relationship to reduce costs and also they can think about building some warehouses to expand and increase the storage capacity (Bence, 1995).

\subsection{Solutions of Environment Problem:}

In order to solve the environment problem there is no better way other that involving employees in creating and maintaining work schedule and working standards. By doing so employees will be refrain from rivalry, protectionism, resistance to change etc. It is also require that the hospital should invest bit more to enhance the working environment (Bence, 1995).

\subsection{Solutions of Management Problem:}

Management problems are another key issue and it also require to be solved immediately. The hospital can recruit more talents for bringing innovations and simultaneously train the existing ones. It is also require that they should involve the employees in the decision making process. Finally, they need to think seriously to recruit a material manager for accelerating the supply chain tasks (Bence, 1995). 
International Journal of Managing Value and Supply Chains (IJMVSC) Vol. 3, No. 2, June 2012

\section{Limitations of the Fishbone Analysis:}

The fishbone analysis is definitely a very effective tool to find out the causes of problems. The fishbone analysis was really helpful to find out the reasons for supply chain problems of the St James Hospital and also come up with solutions to solve those problems. However, in few literatures some drawbacks of the method have been pointed out. Here in this article a brief overlook of those will be provided. Fishbone analysis outlines the causes of the problems but it does not clarify the sequence of the causes (Public Health Infrastructure, 2008). In real life world a problem may occur due to several reasons but the magnitude or extremity of every reason cannot be the same. The fishbone diagram also fails to satisfy this issue (Ruhm, 2004). It also seldom defines the categories clearly and the verification among the causal relationships is also inadequate. It is a gist of outcomes and therefore fails to represents details of the relevant cases (Watson, 2004). Few researchers (Ruhm, 2004, Straker, 2010 and Watson, 2004) outlined that the fishbone diagram and analysis identifies causes under pre-defined categories only and does not relate causes to each other and to each category as well. Another major failure of the diagram is it does not isolate major issues of the problems and presents each in a same way.

\section{Future Researches on Fishbone Analysis:}

As presented in the previous section, the fishbone analysis has some limitations and requires some sorts of enhancement. It only can be done through academic and scientific researches. Future researches on this method can be taken place in areas like sequencing the cause and also how to put more emphasize on the causes of higher magnitudes. Research also can be done in the areas of design of the diagram and drawing of relationships between causes of different categories and sub-categories.

\section{Conclusion:}

This portfolio and article writing on the case study of the St James Hospital and Lucas Engineering was an interesting and new one. The fishbone diagram and analysis was very innovative and efficient way of resolving key issues of the organizations. It has some draw backs but that doesn't minimize the wonderful way of analysis it provides. The case study reveals that the main problems of the hospital were its supply chain management inefficiency and analysis on different classic categories of the fishbone outlined the causes. This article also provides some solutions for resolving those problems. If the hospital can undertake those they can get rid of the ongoing problems of supply chain management and strive forward for future success (Watson, 2004, Wrennal and Markey, 1995 and Straker, 2010).

\section{References:}

[1] American Society for Quality (2005), Fishbone diagram Accessed From: http://www.asq.org/learnabout-quality/cause-analysis-tools/overview/fishbone.html Accessed by: March 2, 2011.

[2] Balanced Scorecard Institute (2007), Basic tools for process improvement, Module 5 - Cause and Effect diagram, Accessed From: http://www.balancedscorecard.org/files/c-ediag.pdf, Accessed by: March 2, 2011. 
International Journal of Managing Value and Supply Chains (IJMVSC) Vol. 3, No. 2, June 2012

[3] Bence, V (1995), ST. James Hospital and Lucas Engineering System Ltd.-A Public/Priavte Sector Collaboration in BPR Project B-The Re-organization of Purchasing and Supplies. Cranfield Centre for Logistics and Transportation, Cranfield University. UK.

[4] Gregory, F. H (1992) Cause, Effect, Efficiency \& Soft Systems Models, Journal of the Operational Research Society, 44 (4), pp 333-344.

[5] Ishikawa, K (1986). Guide to Quality Control. Tokyo, Japan: Asian Productivity Organization.

[6] Ishikawa, K (1990); Introduction to Quality Control; ISBN 4-906224-61-X OCLC 61341428.

[7] Otto, K. (1995) “Course Notes on Design for Assembly, ”Massachusetts Institute of Technology.

[8] Poli, C., Graves, J., and Sunderland, J.E. (1988) Computer-Aided Product Design for Economical Manufacture. ASME Computers in Engineering, 1(4), pp.23-37.

[9] Public Health Infrastructure (2008), Fishbone (Ishikawa) Diagram (Example), Accessed From: http://www.phf.org/infras, html, Accessed by: March 4, 2011.

[10] Ruhm, K. H (2004) Cause and Effect Diagram, Internet Portal "Measurement Science and Technology"; Retrieved from: www.mmm.ethz.ch/dok01/d0000538.pdf, Accessed by: March 5, 2011.

[11] Southern, G (1995), Business Change and Re-engineering: A Brainstorming Approach, Journal of Corporate transformation, 2(1), p.40.

[12] Straker, D. (2010) Cause-Effect Diagram. Retrieved from: Quality Tools:

http://syque.com/quality_tools/toolbook/cause-effect/cause-effect.htm, Accessed by: March 4, 2011.

[13] Sturges, R., and Kilani, M. (1992) Towards an Integrated Design for an Assembly Evaluation and Reasoning System. Computer-Aided Design, 24(2), pp. 67-78.

[14] U.S. Environmental Protection Agency (1993) "Life-Cycle Assessment: Inventory Guidelines and Principles", EPA Report No. EPA/600/R-92/245, Office of Research and Development, Washington, D.C.

[15] Watson, G. (2004). The Legacy Of Ishikawa. Quality Progress, 37(4), pp. 54-47.

\section{Author}

Tarun Kanti Bose is currently serving as an Assistant Professor in the Business Administration Discipline in Khulna University, Bangladesh. He has completed his Masters Degree in Management conducted jointly in University of Greenwich, London, England and Saxion University of applied sciences, Deventer, The Netherlands. He has 10 peer reviewed publications and more than 15 publications in progress.

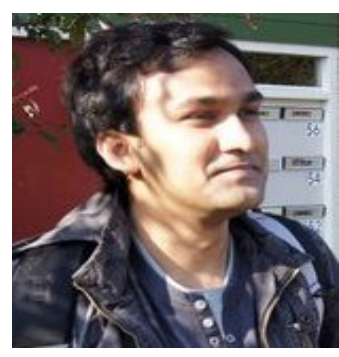

